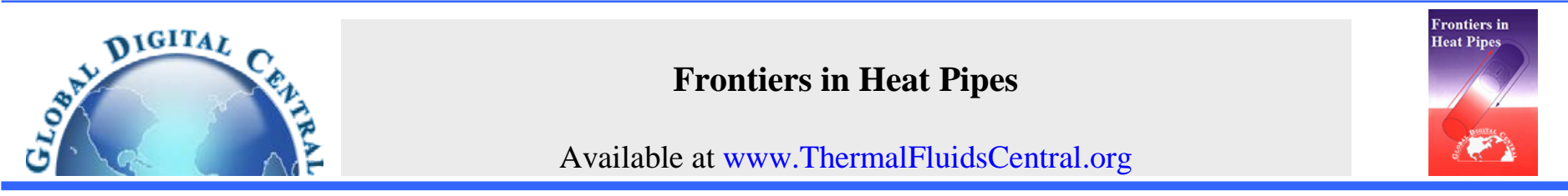

\title{
ANALYSIS OF HEAT PIPE OPERATING PARAMETERS BY RESPONSE SURFACE METHODOLOGY USING COPPER NANOFLUID AS WORKING FLUID
}

\author{
R Senthilkumar* , J Prabakaran, M Karthikeyan \\ ${ }^{a}$ Department of Mechanical Engineering, Annamalai University, Annamalai Nagar, India 608002
}

\begin{abstract}
The performance of a heat pipe is analysed using Response Surface Methodology (RSM) with various input parameters namely heat input, angle of inclination, filling ratio, concentration of copper nanofluid and flow rate of coolant in the condenser over the output response i.e. the thermal efficiency of the heat pipe. The experimental design is developed based on Box - Behnken design method. The influence of vital input parameters and interaction among them are investigated using analysis of variance (ANOVA). The proposed mathematical model in this study has proven to fit and in line with experimental values with a 95\% confidence interval.
\end{abstract}

Keywords: Heat pipe, Copper nanofluid, Thermal efficiency, RSM.

\section{INTRODUCTION}

Heat pipes are considered as passive heat transfer devices that transfer the heat from heat source to sink. The heat pipes can be designed in a myriad of shape, sealed, evacuated vessels with a little amount of working fluid. The vessels are lined with a capillary structure (wick) which allows the condensate to travel through it (Reay and Kew, 2006). The heat pipes are able to operate against gravity and tolerate very low temperature drops between the evaporator and the condenser. The performance of the heat pipe depends on numerous factors like heat input, angle of inclination, filling ratio of the working fluid in the heat pipe, etc. All the operating parameters play a key role and selection of these parameters ultimately depends on the application.

The conventional working fluids used in the heat pipe have poor heat transfer properties compared to solid metals. A new class of heat transfer fluids that are called as “Nanofluids”, which are engineered by suspending ultra-fine metallic or non metallic nano particles in conventional fluids such as water, engine oil, ethylene glycol (Choi, 1995). The experimental results show that the nanofluids have remarkably higher thermal conductivity and greater heat transfer characteristics than conventional pure fluids (Xuan and Li, 2000; Daungthongsuk and Wongwises, 2007; Xuan et.al, 2003). The thermo physical and transport properties of the conventional fluids are improved by adding the nanoparticles in base fluid. The effective thermal conductivity of nanofluids increases with increase in temperature (Das et.al, 2003). This finding makes nanofluids even more attractive as a cooling fluid for heat transfer devices with high energy density.

The thermal enhancement using silver nano-fluid as the working fluid in the grooved heat pipe was studied with 10 and $35 \mathrm{~nm}$ size and reported that the increase in heat pipe wall temperature was lesser than that for a pure water filled heat pipe under various heat loads (Kang et.al, 2006). The enhancement of heat pipe efficiency with R-11refrigerant-nanoparticles (titanium) mixtures was studied. The effects of the charge amount of the working fluid, heat pipe tilt angle on the efficiency of heat pipe has been measured. It has been found that the heat pipe with $0.1 \%$ nanoparticles concentration gives efficiency 1.40 times higher than that with pure refrigerant (Naphon et.al, 2009). The impacts of aqueous copper oxide nanofluids on the thermal performance of a horizontal heat pipe working at steady subatmospheric pressures are investigated and it was reported that the copper nanofluid can significantly enhance heat transfer coefficients of both evaporator and condenser sections and also the maximum heat flux of the heat pipe (Liu and Zhu, 2011).

Response surface methodology (RSM) is a collection of mathematical and statistical techniques for developing, improving and optimizing the process parameters by careful design of experiments. The objective is to optimize a response (output variable) which is influenced by several independent variables (input variables). An experiment is a series of tests, called runs, in which changes are made in the input variables in order to identify the reasons for changes in the output response (Montgomery, 2005; Mohammed, 2010; Gunaraj and Murugan, 1999; Ramkumar and Ragupathy, 2012; Prabakaran et al, 2012). In general the relationship is

$\mathrm{Y}=\mathrm{f}\left(\mathrm{X}_{1}, \mathrm{X}_{2}, \mathrm{X}_{3}, \ldots\right) \pm \varepsilon$

Literature review on heat pipe performance reveals that the optimization of heat pipe using RSM does not have reported so far. Hence the present study employs RSM technique to optimize the operating parameters of heat pipe. The objective of the present investigation is to optimize the heat pipe operating parameters like heat input, angle of inclination, filling ratio, concentration of copper nanofluid and flow rate of the coolant on the condenser by response surface methodology of a copper-water heat pipe with screen mesh wick.

\footnotetext{
*Corresponding author: Email: rsklme@yahoo.com
} 


\section{EXPERIMENTAL ARRANGEMENT AND TEST PROCEDURE}

The experimental setup of heat pipe and thermocouple locations are shown in Fig. 1 and 2 respectively. The evaporator of the heat pipe is heated by a cylindrical electric heater which is attached in the evaporator section of the container. The temperature distributions along the length of the heat pipe have been measured using copper-constantan (T-type) thermocouples. The surface temperature of the heat pipe in adiabatic region is measured using six evenly spaced thermocouples with an uncertainty of $\pm 0.1^{\circ} \mathrm{C}$. In addition, three thermocouples are provided each on the evaporator section, on the condenser section and one each in inlet and outlet of the condenser jacket. The heat pipe is charged with working fluid, which approximately corresponds to the amount required to fill the evaporator which is nearly to $40 \mathrm{ml}$. At the beginning of the experiment, the evaporator temperature is $30^{\circ} \mathrm{C}$ for all experiments for comparison of results.

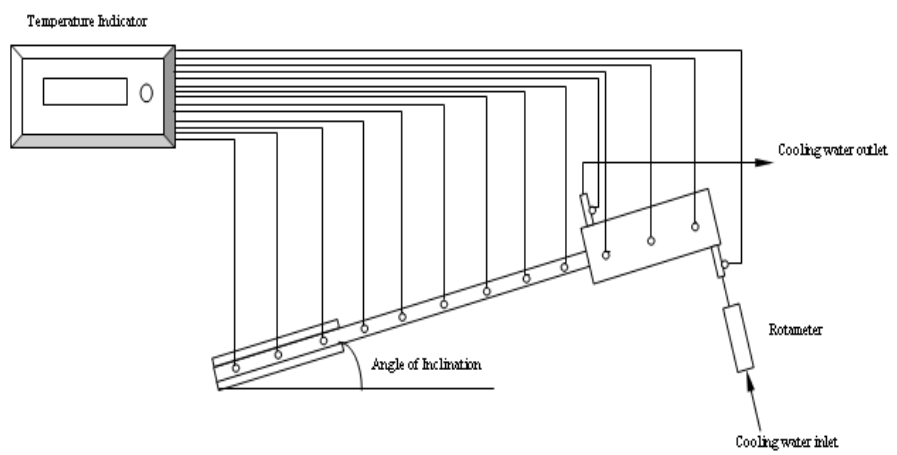

Fig. 1 Experimental arrangement

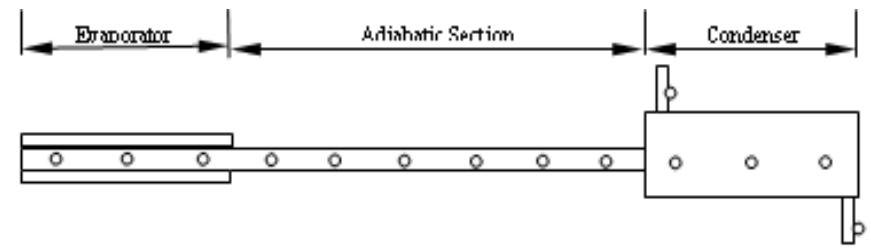

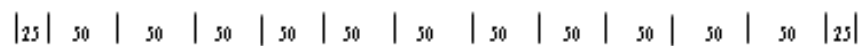

Fig. 2 Thermocouple locations of heat pipe

The cooling water is circulated in the cooling jacket to remove the heat of the working fluid. This cooling jacket is attached to the condenser section which is located at the end of the heat pipe. The heat pipe has the capability to transmit the heat through the internal structure. Therefore, an abrupt increase in the wall temperature could harm the heat pipe if the heat is not rejected at the condenser properly. Hence, the cooling water is first dispersed through the condenser jacket, before the heat is supplied to the evaporator. The condenser section of the heat pipe is cooled using water flowing through a circumferential water jacket. The cooling water flow rate is measured by a rotameter with an uncertainty of $\pm 1 \%$ and the flow rate is kept constant at 0.08 $\mathrm{kg} / \mathrm{min}$. The initial temperature of cooling water is maintained at $28^{\circ} \mathrm{C}$ at the time of starting the experiments. The inlet and outlet temperatures of the cooling water are computed using two copper constantan thermocouples.

The experimental specifications are given in Table 1. The adiabatic section of the heat pipe is entirely covered with glass wool insulation to avoid the heat loss. The amount of heat loss from the evaporator and condenser surface is negligible due to the proper insulation in the heat pipe surface. The power input given to the evaporator section of the heat pipe is gradually increased to the preferred power level. The surface temperatures at six different locations along the adiabatic section of heat pipe are measured at regular time intervals until the heat pipe attains the steady state condition. Concurrently, the evaporator wall temperatures, condenser wall temperatures, water inlet and outlet temperatures in the condenser zone are also measured.

Once the steady state is reached, the input power is turned off and cooling water is permitted to flow through the condenser to cool the heat pipe and to make it ready for further experimental purpose. The steady state is defined as the variation in temperature which is less than $\pm 0.1^{\circ} \mathrm{C}$ for subsequent time intervals. Then the power is increased to the next level and the heat pipe is tested for its performance. The experimental procedure is repeated for different heat inputs and different inclinations of pipe to the horizontal and observations are recorded. The output heat transfer rate from the condenser is calculated by applying an energy balance to the condenser flow. The vacuum pressure in the inner side of the heat pipe is monitored by a vacuum gauge, which is attached in the condenser end of the heat pipe. The initial vacuum pressure inside the heat pipe is 70 to $75 \mathrm{~cm}$ of $\mathrm{Hg}$, because at higher vacuum condition the heat pipe performs better. When the heat pipe is placed in the reverse direction, i.e. the evaporator is kept above the condenser, the condensate has to return back to the evaporator by the capillary action of wick only and against the gravity. This result in the reduction in the performance of the heat pipe compared to the performance of gravity assisted heat pipe.

Table 1 Specifications of heat pipe

\begin{tabular}{|l|l|}
\hline Properties & Specifications \\
\hline Heat pipe material & Copper \\
\hline Wick material & Stainless steel (two layers) \\
\hline Total length of pipe, $\mathrm{m}$ & 0.6 \\
\hline Evaporator length, $\mathrm{m}$ & 0.15 \\
\hline Adiabatic length, $\mathrm{m}$ & 0.3 \\
\hline Condenser length, $\mathrm{m}$ & 0.15 \\
\hline Condenser outer dia, $\mathrm{m}$ & 0.036 \\
\hline Condenser inner dia, $\mathrm{m}$ & 0.030 \\
\hline Outer diameter of the pipe, $\mathrm{m}$ & 0.020 \\
\hline Inner diameter of the pipe, $\mathrm{m}$ & 0.0176 \\
\hline Wick permeability, ${ }^{2}$ & $2.16 \mathrm{x} 10^{-6}$ \\
\hline Wire mesh diameter, $\mathrm{m}$ & 0.183 \\
\hline Heat Input, W & $30,40,50,60$ and 70. \\
\hline Heat pipe inclination & $0^{\circ}, 15^{\circ}, 30^{\circ}, 45^{\circ}, 60^{\circ}, 75^{\circ}$ and $90^{\circ}$ \\
\hline Working fluid & Copper nanofluid, $100 \mathrm{mg} /$ lit \\
\hline Wick mesh size & $60 / \mathrm{sq}$ inch \\
\hline Wick Porosity $(\varepsilon)$ & 0.6431 \\
\hline
\end{tabular}

\section{RESULTS AND DISCUSSIONS}

In this experimental study the performance of the heat pipe is analyzed by response surface methodology (RSM). Box Behnken design method is employed with five input parameters namely heat input (A), angle of inclination (B), filling ratio (C) concentration of copper nano particle in the base fluid (D) and the flow rate of the coolant in the condenser (E) over the output response as thermal efficiency. DESIGN-EXPERT software is used for this analysis. Table 2 shows the range of input parameters. In RSM -1 means the minimum and +1 denotes the maximum value of each input parameters.

The computed values of the thermal efficiency are entered in the software design matrix. The Box-Behnken response surface methodology is used to develop the relationship between the experimental variables and the response that is thermal efficiency. A regression analysis is carried out to develop a best fit of the model to the experimental data, which are used to generate response surface plots. Table 3 shows the analysis of variance (ANOVA). The values of "Prob>F" less than 0.05 indicates model terms are significant. The value 0.05 shows that the regression is statistically significant at a $95 \%$ confidence level $(P<0.05)$. For the present case heat input $(A)$, angle 
of inclination (B) and filling ratio (C) are playing significant effect than the concentration (D) and flow rate (E). The square values of angle of inclination (B), filling ratio (C), concentration (D) and flow rate (E) are also having significant effect on the performance of the heat pipe. The interaction effect between heat input and angle of inclination (AB) also has significant effect. The interaction effect of heat input with concentration (AD) and heat input with filling ratio (AC) also made some significant effect on the efficiency. The other effects like AE, BC, $\mathrm{BD}, \mathrm{BE}, \mathrm{CD}, \mathrm{CE}$ and $\mathrm{DE}$ are insignificant.

Table 2 Process Parameters

\begin{tabular}{|l|c|c|c|}
\hline \multirow{2}{*}{\multicolumn{1}{|c|}{ Parameter }} & \multicolumn{3}{c|}{ Level } \\
\cline { 2 - 4 } & -1 & 0 & +1 \\
\hline Heat input, W & 30 & 50 & 70 \\
\hline Angle of inclination, Deg & 0 & 30 & 60 \\
\hline Filling ratio, \% & 25 & 75 & 125 \\
\hline Concentration, mg/lit & 25 & 75 & 125 \\
\hline Flow rate, kg/s & 0.06 & 0.1 & 0.14 \\
\hline
\end{tabular}

The "Pred R-Squared" value of 0.9843 (coefficient of determination) is in responsible agreement with “Adj R-Squared” of 0.9717. Adequate precision measures the signal to noise ratio. A ratio greater than 4 is desirable. Here the ratio of 30.5142 indicates an adequate signal. This model can be used to navigate the design space. The model $\mathrm{F}$ value is 78.34 and a probability value is less than 0.001 which indicates that the model is significant for to finding the thermal efficiency of the heat pipe. The sum of squares due to lack of fit, or more tersely a lack-of-fit sum of squares, is one of the components of a partition of the sum of squares in an analysis of variance, used in the numerator in an F-test. Based on ANNOVA, different coefficients were estimated to develop the following empirical relation to predict the thermal efficiency of the heat pipe. The values are Prob $>\mathrm{F}$ less than the 0.05 indicates that the terms are significant and values are greater than the 0.1 indicates that the insignificants. The lack of fit $\mathrm{F}$ value is 3.558 means the lack of fit not significant and it relative to the pure error. Non significant of lack of fit is good for model to fit. Based on the ANNOVA, the following empirical relation was developed to predict the thermal efficiency of the heat pipe. The $\mathrm{df}$ denotes the degree of freedom of the model and that value is 20. It is the number of values in the final calculation of a statistic that are free to vary. Mean squares are used in analysis of variance and are calculated as a sum of squares divided by its appropriate degrees of freedom.

Thermal Efficiency $=-33.985+0.40925 \mathrm{~A}+0.3164 \mathrm{~B}+0.3729 \mathrm{C}$ $+0.4217 \mathrm{D}+264.6823 \mathrm{E}+0.00263 \mathrm{AB}+0.00119 \mathrm{AC}-0.00124 \mathrm{AD}-$ $0.025 \mathrm{AE}+0.000345 \mathrm{BC}+0.00062 \mathrm{BD}+0.15417 \mathrm{BE}-0.00002 \mathrm{CD}+$ $0.47875 \mathrm{CE}-0.2475 \mathrm{DE}+0.0001 \mathrm{~A}^{2}-0.007442 \mathrm{~B}^{2}-0.002803 \mathrm{C}^{2}-$ $0.002348 \mathrm{D}^{2}-1484.896 \mathrm{E}^{2}$.

The thermal efficiency of the heat pipe is calculated as the ratio of heat rejection in the condenser section to the heat input at the evaporator section (Naphon, 2009). The working fluid in this analysis is copper nanofluid. The base fluid used in the copper nanofluid is DI water. The equation 2 valid for the experiments within the range of heat pipe operation mentioned in the table 2.It is observed from Fig. 3-6 that the thermal efficiency of heat pipe increases linearly with an increase the heat input in the evaporator section. The thermal efficiency of the heat pipe increases with increase in heat flux, due to the fact that the temperature gradient between the evaporator section and condenser sections increases. For higher values of heat input in the evaporator section, the heat generated in the surface is more and the working medium which is in the form of vapour moves vigorously into the condenser section. The cooling water in the condenser absorbs this excessive heat and as a result, the efficiency of the heat pipe increases.
The maximum heat input given to the evaporator based on the heat pipe heat transfer limitations (Table 4).

From the figures $(3,7,8 \& 9)$ it is evident that the heat pipe efficiency increases with the increase in the tilt angle up to certain angle and then decreases. This is due to the fact that, the gravitational force has a significant effect on the flow of working fluid between the evaporator section and the condenser section in addition to capillary action of wick. The thermal efficiency of the heat pipe reaches a maximum at $45^{\circ}$ tilt angle afterwards the heat pipe thermal efficiency tends to decrease. This may be due to the strong formation of the liquid film at the inner side of condenser section resulting in the high thermal resistance between the vapour of the working fluid and the cooling medium in the condenser. From the figures 4, 7, 10 \&11, the thermal efficiency is high at a $100 \%$ filling of the evaporator. If the filling ratio more than the volume of the evaporator, the space available for the flow of the vapour is reduced. At lower filling ratio, the amount of working fluid used to carry away the heat from the evaporator is reduced, so that the efficiency heat pipe is lowered. Figure 5, 8, $10 \& 12$ show the variations of thermal efficiency of the heat pipe with concentration of the copper nanofluid. Thermal efficiency increases with the concentration of copper oxide nano fluid in the base fluid. The value of efficiency is maximum at $100 \mathrm{mg} / \mathrm{lit}$ of concentration of copper oxide nano particle in the base fluid. More than that value, the performance of the heat pipe gets reduced due to the agglomeration of nano particles which block of mesh holes in the wick. The variation effect of flow rate of coolant in the condenser is very less than the other parameters.

Figure 13 shows the optimization plot with a desirability of 0.993 generated by RSM. It shows that the optimum value of the thermal efficiency is $50 \%$ when the heat input is $69.94 \mathrm{~W}$, at $43.34^{\circ}$ inclination, filling ratio of $100.15 \%$, at a concentration of CUO $82.93 \mathrm{mg} / \mathrm{lit}$ and flow rate $0.10 \mathrm{~kg} / \mathrm{min}$.

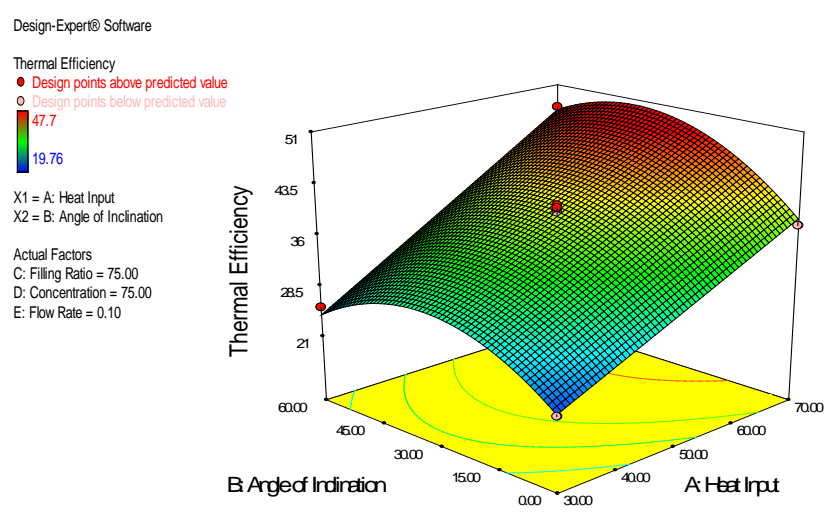

Fig. 3 Effect of heat input and angle of inclination

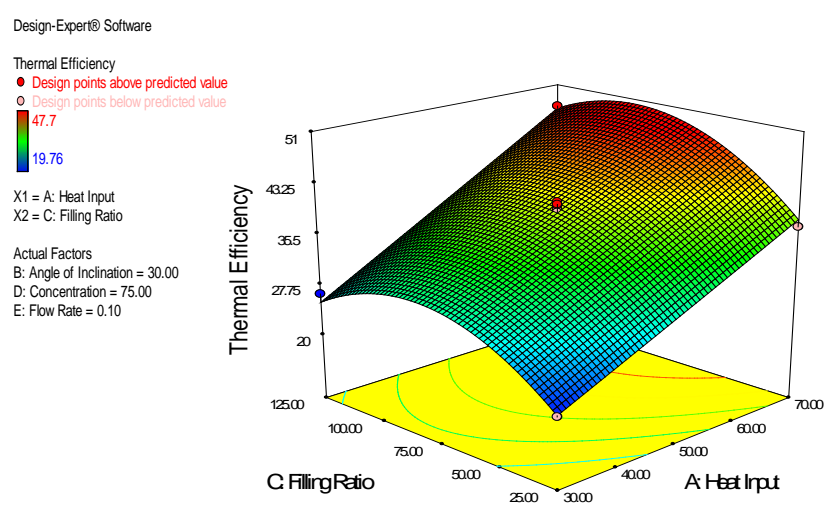

Fig. 4 Effect of heat input and filling ratio 


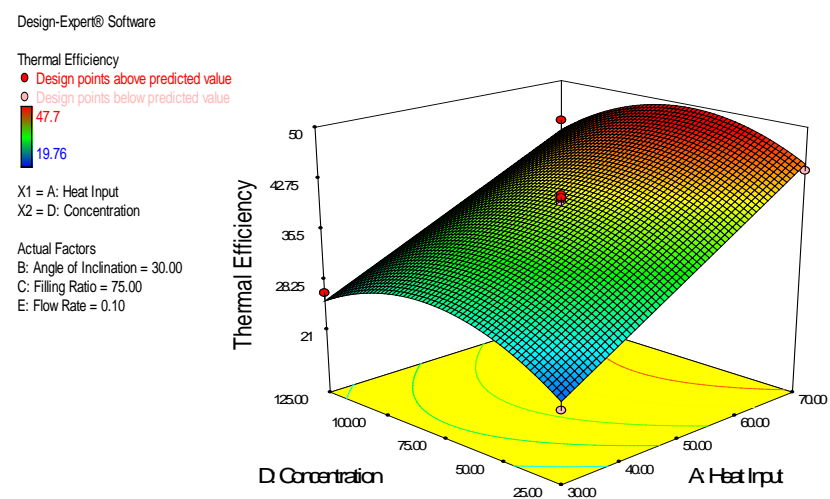

Fig. 5 Effect of heat input and concentration

Design-Expert@ Sofware

Thermal Efficiency

- Design points above predicted value
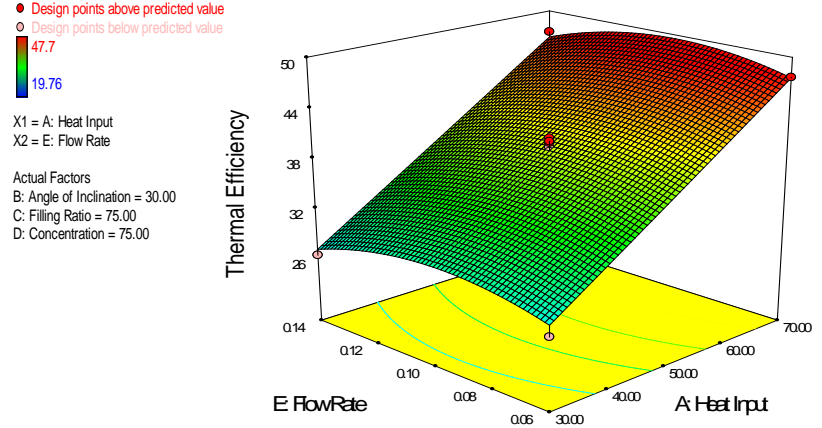

Fig. 6 Effect of heat input and flow rate

Design-Expert@ Sotware

Thermal Efficiency

- Design points above predicted value

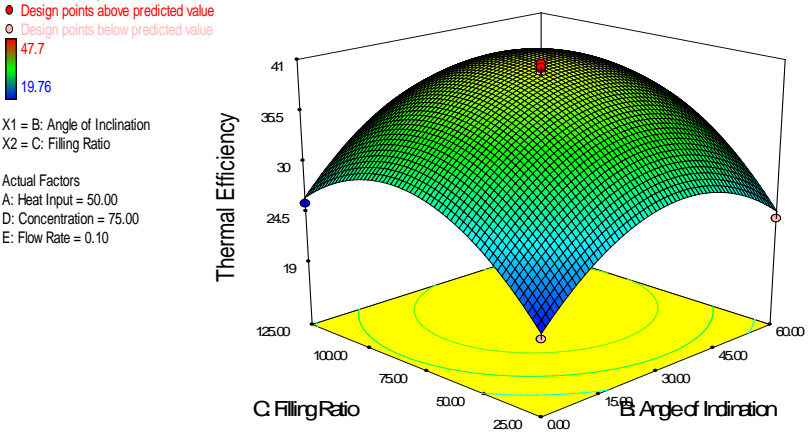

Fig. 7 Effect of angle of inclination and filling ratio

Table 4 Heat Transfer Limitations

\begin{tabular}{|l|c|}
\hline \multicolumn{1}{|c|}{ Limitation } & Values in $W$ \\
\hline Capillary Limit & 77 \\
\hline Sonic Limit & 65400 \\
\hline Entrainment Limit & 4638 \\
\hline Boiling Limit & 642 \\
\hline
\end{tabular}

Table 3 ANOVA for Response Surface Quadratic Model - Thermal Efficiency

\begin{tabular}{|c|c|c|c|c|c|}
\hline Source & $\begin{array}{c}\text { Sum of } \\
\text { Squares }\end{array}$ & $d f$ & $\begin{array}{l}\text { Mean } \\
\text { Square }\end{array}$ & $\begin{array}{c}F \\
\text { Value }\end{array}$ & $\begin{array}{l}p \text {-value } \\
\text { Prob }>F\end{array}$ \\
\hline Model & 2744.54 & 20 & 137.23 & 78.34 & $<0.0001$ \\
\hline A-Heat Input & 1549.21 & 1 & 1549.2 & 884.42 & $<0.0001$ \\
\hline $\begin{array}{l}\text { B-Angle of } \\
\text { Inclination }\end{array}$ & 114.87 & 1 & 114.87 & 65.58 & $<0.0001$ \\
\hline C-Filling Ratio & 188.65 & 1 & 188.65 & 107.7 & $<0.0001$ \\
\hline $\begin{array}{l}\text { D- } \\
\text { Concentration }\end{array}$ & 0.001 & 1 & 0.0012 & 0.001 & 0.9791 \\
\hline E-Flow Rate & 3.432 & 1 & 3.4318 & 1.959 & 0.1739 \\
\hline $\mathrm{AB}$ & 9.986 & 1 & 9.9856 & 5.701 & 0.0248 \\
\hline $\mathrm{AC}$ & 5.664 & 1 & 5.6644 & 3.234 & 0.0842 \\
\hline $\mathrm{AD}$ & 6.150 & 1 & 6.1504 & 3.511 & 0.0727 \\
\hline $\mathrm{AE}$ & 0.002 & 1 & 0.0016 & 0.001 & 0.9761 \\
\hline $\mathrm{BC}$ & 1.071 & 1 & 1.0712 & 0.612 & 0.4415 \\
\hline $\mathrm{BD}$ & 3.460 & 1 & 3.4596 & 1.975 & 0.1722 \\
\hline $\mathrm{BE}$ & 0.137 & 1 & 0.1369 & 0.078 & 0.7821 \\
\hline $\mathrm{CD}$ & 0.010 & 1 & 0.0100 & 0.006 & 0.9404 \\
\hline $\mathrm{CE}$ & 3.667 & 1 & 3.6672 & 2.094 & 0.1603 \\
\hline $\mathrm{DE}$ & 0.980 & 1 & 0.9801 & 0.560 & 0.4614 \\
\hline $\mathrm{A}^{2}$ & 0.014 & 1 & 0.0140 & 0.008 & 0.9296 \\
\hline $\mathrm{B}^{2}$ & 391.47 & 1 & 391.48 & 223.49 & $<0.0001$ \\
\hline$C^{2}$ & 428.451 & 1 & 428.45 & 244.6 & $<0.0001$ \\
\hline $\mathrm{D}^{2}$ & 300.715 & 1 & 300.72 & 171.67 & $<0.0001$ \\
\hline$E^{2}$ & 49.262 & 1 & 49.26 & 28.123 & $<0.0001$ \\
\hline Residual & 43.792 & 25 & 1.7517 & & \\
\hline Lack of Fit & 40.917 & 20 & 2.0458 & 3.558 & 0.0820 \\
\hline R-Squared & \multicolumn{2}{|c|}{0.9843} & & & \\
\hline Adj R-Squared & \multicolumn{2}{|c|}{0.9717} & & & \\
\hline Pred R-Squared & \multicolumn{2}{|c|}{0.9398} & & & \\
\hline Adeq Precision & \multicolumn{2}{|c|}{30.5142} & & & \\
\hline
\end{tabular}

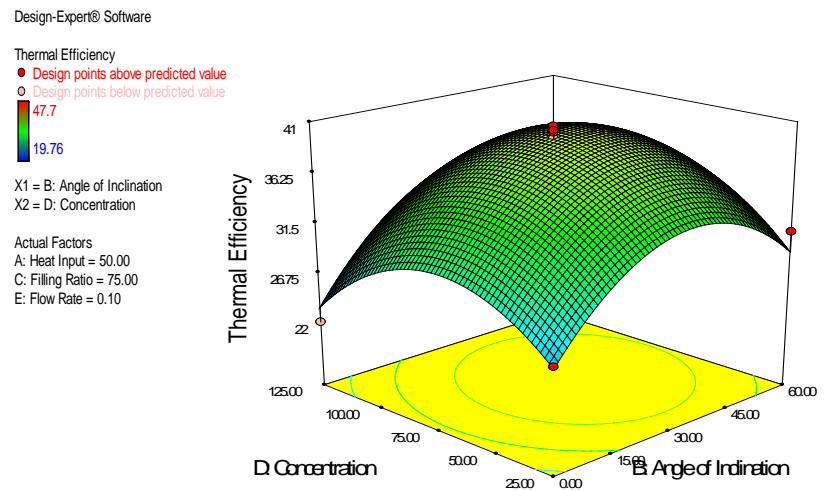

Fig. 8 Effect of angle of inclination and concentration 

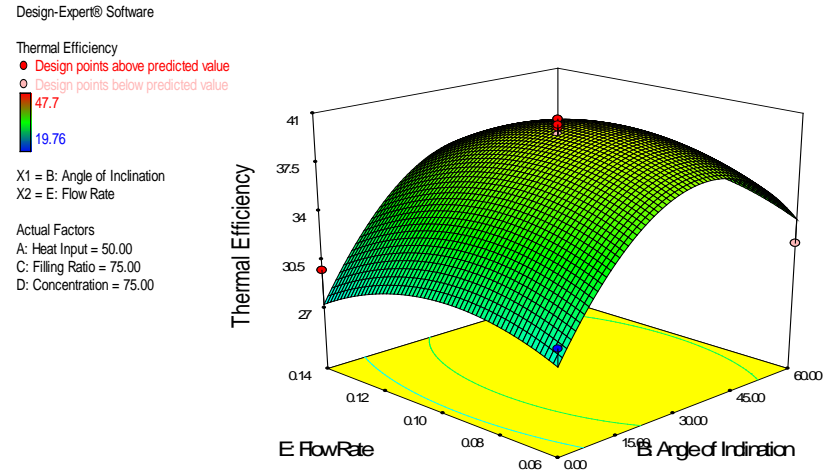

Fig. 9 Effect of angle of inclination and flow rate

Design-Expert@ Softwar
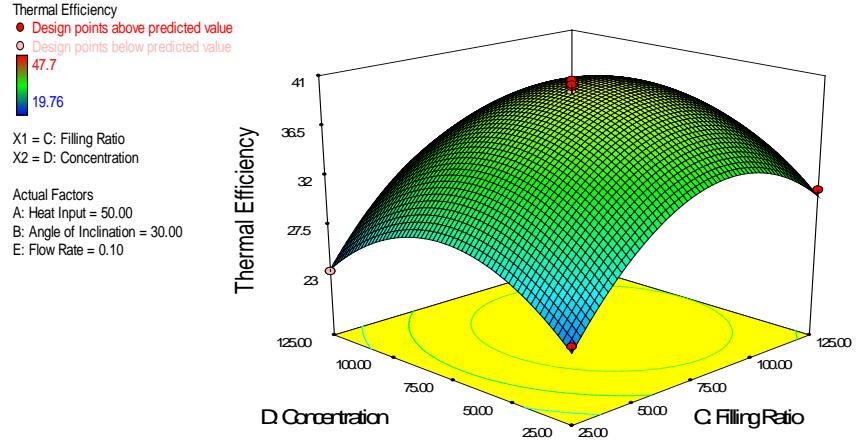

Fig. 10 Effect of filling ratio and concentration
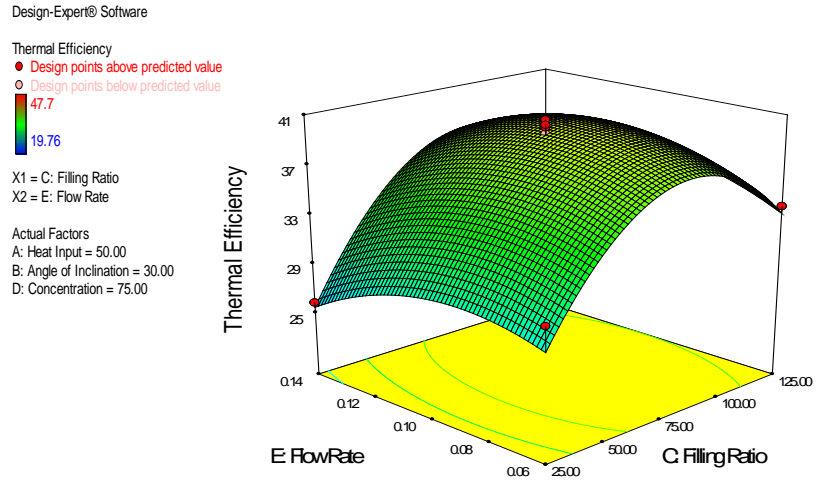

Fig. 11 Effect of filling ratio and flow rate
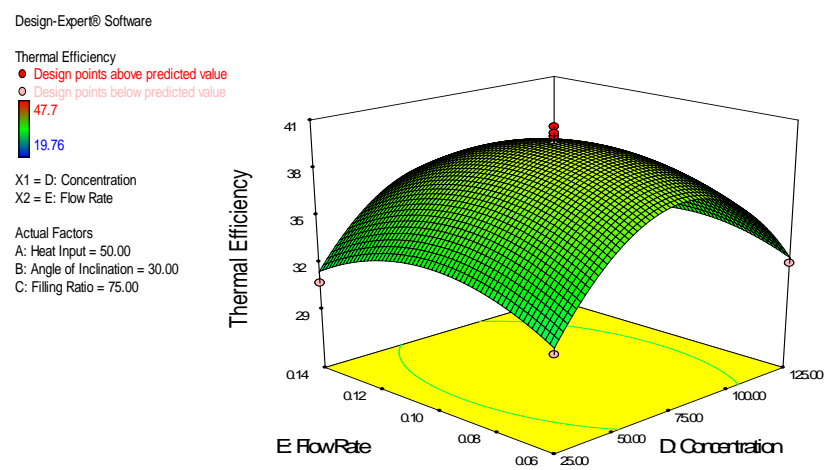

Fig. 12 Effect of concentration and flow rate
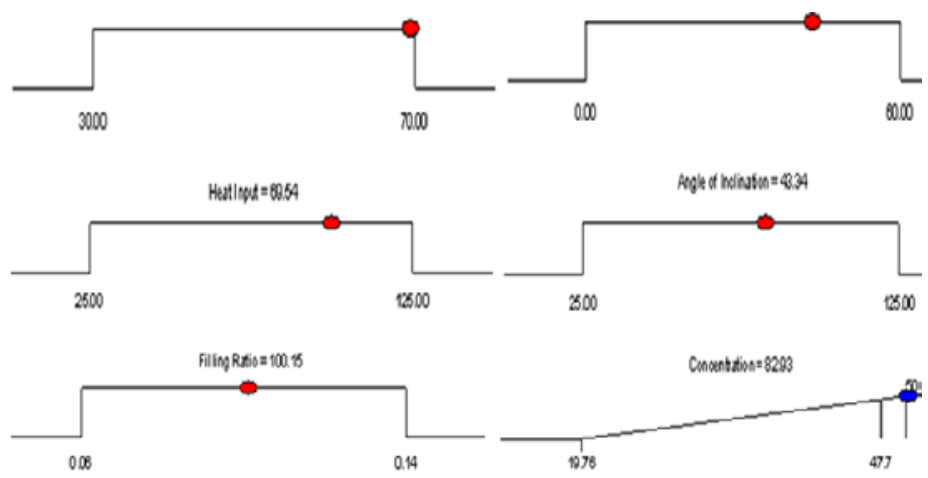

Alowhate $=0.10$

Themal Effienoy $=5023$

Fig. 13 Optimization plot

\section{VALIDATION OF MODEL}

In order to confirm the optimization result, the experiment was conducted with $70 \mathrm{~W}$ heat input at $45^{\circ}$ inclination of the heat pipe, filling ratio of $100 \%$, concentration $85 \mathrm{mg} / \mathrm{lit}$ with a flow rate of 0.1 $\mathrm{kg} / \mathrm{min}$. The thermal efficiency of the heat pipe have been found as $50.42 \%$ which is closer to the optimum value. The values of the efficiency obtained from the experimental and predicted values are compared to examine the validity of the model and compare the relative factors. The confirmation tests are conducted and the errors are tabulated in the Table 5. The findings show that the errors between the experimental and predicted values are less than $2 \%$. It denotes that the predicted model is efficient.

Table 5 Comparison of predicted and experimental values

\begin{tabular}{|c|c|c|c|c|c|c|c|c|}
\hline Sl.No & \multicolumn{5}{|c|}{ Factors } & \multicolumn{2}{|c|}{ Efficiency } & $\begin{array}{c}\text { Error } \\
\text { (\%) }\end{array}$ \\
\cline { 2 - 9 } & $\mathrm{A}$ & $\mathrm{B}$ & $\mathrm{C}$ & $\mathrm{D}$ & $\mathrm{E}$ & $\begin{array}{l}\text { Predi } \\
\text { cted }\end{array}$ & $\begin{array}{c}\text { Experi } \\
\text { mental }\end{array}$ & \\
\hline 1 & 30 & 0 & 75 & 75 & 0.1 & 22.06 & 21.80 & 1.19 \\
\hline 2 & 50 & 60 & 75 & 75 & 0.06 & 33.54 & 32.80 & 2.26 \\
\hline 3 & 70 & 30 & 125 & 75 & 0.1 & 47.18 & 47.52 & 0.72 \\
\hline 4 & 50 & 60 & 25 & 75 & 0.1 & 24.67 & 23.85 & 3.44 \\
\hline 5 & 50 & 30 & 125 & 75 & 0.14 & 34.23 & 33.20 & 3.01 \\
\hline $\begin{array}{c}\text { Confir } \\
\text { matio } \\
\text { n test }\end{array}$ & 70 & 45 & 100 & 85 & 0.1 & 50.29 & 50.42 & 0.26 \\
\hline
\end{tabular}

\section{CONCLUSION}

In this paper, the experimental results showed the thermal efficiency of the heat pipe and the statistical analysis results demonstrated that the effects of various operating parameters on the thermal efficiency. Empirical relation for thermal efficiency was developed to correlate dominant input parameters like heat input, angle of inclination, filling ratio, concentration of copper nanofluid and the flow rate of coolant using Response Surface Methodology. The influence of input parameters on the performance of heat pipe was analyzed based on the developed relation by RSM. The predicted value of RSM are very closer to the experimental results and it has reduced the number of experiments, because RSM provides useful interaction between different variables of the system. In the desirability function approach, the value of desirability was 0.993 for the RSM model very close to 1 . The predicted RSM model is found to be capable of predictive thermal efficiency of heat pipe.RSM showed a better 
accuracy and capability of generalization with the design of experiments.

\section{ACKNOWLEDGMENT}

The authors thank the authorities of Annamalai University for providing the necessary facilities in order to accomplish this piece of work.

\section{NOMENCLATURE}

$\begin{array}{ll}A & \text { heat input, } W \\ B & \text { angle of inclination. Deg } \\ C & \text { filling ratio, \% } \\ D & \text { concentration, } \mathrm{mg} / \mathrm{lit} \\ E & \text { flow rate. } \mathrm{kg} / \mathrm{s} \\ Y & \text { response of RSM } \\ X & \text { input variables } \\ f & \text { mathematical function) }\end{array}$

Greek Symbols

$\varepsilon \quad$ measurement error

Subscripts

$1,2 \ldots \quad$ variable at points

\section{REFERENCES}

Choi, S.U.S., 1995, "Enhancing Thermal Conductivity of Fluids with Nanoparticles, Developments and Applications of Non-Newtonian Flows”, FED, 231, 99-105.

Das,S.K., Putra, N., Thiesen, P., and Roetzel, W., 2003, “Temperature Dependence of Thermal Conductivity Enhancement for Nanofluids”, Journal of Heat Transfer, 125, 567-574.

http://dx.doi:10.1115/1.1571080

Daungthongsuk, W., and Wongwises, S., 2007, “A Critical Review of Convective Heat Transfer of Nanofluid”, Renewable and Sustainable Energy Reviews, 11, 797-817.

http://dx.doi.org/10.1016/j.rser.2005.06.005

Gunaraj, V., and Murugan, N., (1999) Application of Response Surface Methodology for Predicting Weld Bead Quality in Submerged Arc Welding of Pipes. Journal of Materials Processing Technology, 88(1-3),pp. 266-275.

http://dx.doi.org/10.1016/S0924-0136(98)00405-1

Kang ,S.W., Wei, W.C., Tsai, S.H., and Yang S.U., 2006, "Experimental Investigation of Silver Nano-Fluid on Heat Pipe
Thermal Performance”, Applied Thermal Engineering, 26(17-18), 2377-2382.

http://dx.doi.org/10.1016/j.applthermaleng.2006.02.020

Liu, Z.H., and Zhu, Q.G., 2011, “Application of Aqueous Nanofluids in a Horizontal Mesh Heat Pipe”, Energy Conversion and Management, 52(1), 292-300.

http://dx.doi.org/10.1016/j.enconman.2010.07.001

Mohammed, J.K., Aziz, H.M., Yosoff, M.S., and Adlan, N., 2010, "Application of Response Surface Methodology (RSM) for Optimization of Ammonical Nitrogen Removal From Semi-Aerobic Landfill Leachate Using Ion Exchange Resin”, Desalination, 254, 154161.

http://dx.doi.org/10.1016/j.desal.2009.12.002

Montgomery, C.C., 2005, Design and Analysis of Experiments, John Wiley \& sons, USA.

Naphon, P., Thongkum, D., and Assadamongkol, P., 2009, "Heat Pipe Efficiency Enhancement with Refrigerant-Nanoparticles Mixtures", Energy Conversion and Management, 50(3), 772-776. http://dx.doi.org/10.1016/j.enconman.2008.09.045

Prabakaran, J., Vaidyanathan, S., and Kanagarajan. D., 2012, "Establishing Empirical Relation to Predict Temperature Difference of Vortex Tube Using Response Surface Methodology”, Journal of Engineering Science and Technology, 7(6), 722 - 731.

Ramkumar, R., and Ragupathy, A., 2012, “Application of Response Surface Methodology (RSM) for Optimization of Operating Parameters and Performance Evaluation of Cooling Tower Cold Water Temperature”, An International Journal of Optimization and Control: Theories \& Applications, 2(1), 39-50.

http://dx.doi.org/10.11121/ijocta.01.2012.0093

Reay, D.A., and Kew P.A., 2006, Heat Pipes, Butterworth-Heinemann, Oxford press.

Xuan, Y., and Li, Q., 2000, "Heat Transfer Enhancement of Nanofluids”, International Journal of Heat and Fluid Flow, 21, 58-64. http://dx.doi.org/10.1016/S0142-727X(99)00067-3

Xuan, Y. and Li, Q., 2003, "Investigation on Convective Heat Transfer and Flow Features of Nano-Fluids", Journal of Heat Transfer, 125 151-155.

http://dx. doi:10.1115/1.1532008 